\title{
0 \\ Associations among the Five Components within COSO Internal Control- Integrated Framework as the Underpinning of Quality Corporate Governance
}

\author{
Kirsten Rae ${ }^{1}$, John Sands ${ }^{2}$ and Nava Subramaniam ${ }^{3}$
}

\begin{abstract}
This paper examines the associations among COSO components and how they affect the monitoring function of organisations. Five components of an effective internal control system are described using the framework designed by COSO (1992) and have been selected because they have been identified as underpinning quality corporate governance. Structural equation modelling (SEM) was used first to run confirmatory factor analysis to determine the measurement models for the five COSO components. The COSO report (1992) described the internal control framework as a multidirectional iterative and situational (contingent) process. The primary structural model was designed to reflect the one-way directional associations in the model described and shown in Exhibit 1 within the COSO report (1992). SEM analyses were conducted to test the hypotheses. Additional secondary SEM analyses were undertaken to investigate the reciprocal associations suggested in the COSO report (1992).

Findings from the primary SEM analysis provide partial support for associations among the COSO components and enhanced monitoring quality that leads to good corporate governance. The results show that control environment is associated with three dimensions of information and communication (information accuracy, information openness, communication and learning). Additionally, two dimensions of information and communication (communication and learning and information feedback flow) were found to be associated with risk assessment. An indirect association is supported by the results between control environment and risk assessment through the associations among three dimensions of information and communication (information accuracy, information openness and information feedback flow. Risk assessment is associated with control activities, which is subsequently associated with monitoring.
\end{abstract}

\footnotetext{
${ }^{1}$ Corresponding Author, University of Southern Queensland, Email: Kirsten.Rae@usq.edu.au

${ }^{2}$ University of Southern Queensland

${ }^{3}$ RMIT
} 
The results of the additional secondary SEM analyses supported the reciprocal associations among risk assessment, control activities, or monitoring and dimensions of information and communication, as are suggested in the COSO report (1992).

Companies that draw on COSO's internal control framework should benefit from a better understanding of the direct, indirect, and reciprocal associations among the components of internal control systems. The benefits gained from this better understanding may assist companies to enhance their corporate governance practices that lead to the achievement of operational, financial reporting and compliance objectives.

\section{JEL Classification: M14, M40, M41, M50, G34}

Keywords: control environment, ethical environment, information and communication, risk assessment, internal control, control activities, monitoring, corporate governance.

\section{Introduction}

Among the emerging issues in corporate governance, Banerjee and Gupte (2015) identified "Tone in the middle" culture, and unwise risk-taking are the new warning signs to ensure that the directors do not remain the last link in the information chain. Further, Mandaci and Kahyaoglu (2012) recognised that increased business complexity and the corporate scandals consequences has warranted widening the scope of internal auditing in recent years, and asserted that it is fundamental for internal auditing to contribute to the Enterprise Risk Management (ERM) and corporate governance in an organization. An effective internal control system requires identifyiag and understanding the dimensions of the controls and their importance in achieving the results of an organization (Imoniana, Costa Luiza, Alberto, and Alves, 2011). In their study, Imonianna et al (2012) used the Committee of Sponsoring Organizations' (COSO) five internal control components. David Landsittel, the COSO Chairman, confirmed in an interview that while the framework remains relevant "...we need to update the framework to address significant changes in governance...” (Tidrick, 2012, p. 9).

COSO includes the "tone at the top" in its control environment in its 1992 Internal Control Integrated Framework, which conceptualises an effective internal control system. This framework was developed as a foundation to improve mutual understanding among all stakeholders by offering a common language, facilitating more effective communication, and helping businesses achieve their established goals (COSO, 1992, p. 9). In the 1992 report, the relationship among the five COSO components of internal control were discussed extensively and illustrated comprehensively in Exhibit 1 of that report (COSO, 1992). The COSO report (1992, p. 18) concluded that "...internal control is not a serial process...It is a multidirectional iterative process in which almost any component can and will influence another". Also, there is an implicit situational or contingency influence based on comments that "...internal control systems (may) operate at different levels (at one time and)...a particular system may operate differently at different times" (COSO, 1992, p. 20, parentheses added). One of the stated actions from the Internal Control - Integrated Framework is to use it as an established basis for academic research to investigate how to provide guidance for future enhancements (COSO, pp. 8-9). 
In 2006, the COSO task force released a guidance document for internal controls that was requested by the US Securities and Exchange Commission (SEC). The purpose for this guidance is to place significant emphasis on the role of strengthening internal control in smaller public companies. Also, COSO announced in November 2010, that a project will be undertaken to review and modernise the Internal Control Integrated Framework. These enhancements by $\mathrm{COSO}$ are likely to be designed to strengthen corporate governance to mitigate the likelihood of corporate failures and to increase capital market transparency. However, in Australia the 'tone in the middle' should be considered because Justice Owen noted, in the HIH Royal Commission Report, the role middle management have in the governance system of companies and their need to be considered as "responsible for undesirable corporate governance practices" (duPlessis, Hargoven, Bagaric, and Harris, 2015, p 136).

Some authors (e.g., Simmons, 1997a; Rittenberg, 2006; Callaghan; 2007) have discussed the COSO conceptual framework to provide some clarity and guidance. Much past research has largely examined each COSO component separately (e.g. Aikins, 2011; Arena and Azzone 2009; Brief, Dukerich, Brown and Brett, 1996; Cohen, Krishnamoorthy and Wright, 2002). Some studies have examined only two components and found associations between monitoring (management oversight such as monitoring) and control activities (Agbejule \& Jokipii, 2009; Goodwin-Stewart \& Kent, 2006). Another study examined only a few of the components (Rae, Subramaniam \& Sands, 2008). However, a literature search could not identify any study that has tested the five components of COSOs Internal Control Framework using rigorous statistical analysis. Imonianna et al (2012) did examine the five component of control but limited their quantitative analysis to a series of Pearson correlation coefficient analyses that were used to identify associations among 33 questions about the five components of control. Also, their discussion based on a qualitative analysis of answers to unstructured questions provides some possible links between components but these cannot be generalised due to only 5 participants being interviewed in the study. In conclusion, based on this review, to date no study has been identified that examined, statistically, the significance of the associations among these five components as described in the COSO report (1992) have been investigated. From an Australian perspective, the 'tone in the middle' issue has not been examined.

Therefore, a study into the associations among the five COSO interrelated components by Australian middle management is warranted and timely based on literature reviewed above, guidance releases, and review announcements. The purpose of this study will be to investigate the associations among the five COSO interrelated components as discussed and illustrated in COSO (1992) report. The findings should provide guidance for the design of control activities within organisations that will underpin the corporate governance quality. As such, this current study is expected to add to academic as well as practitioner knowledge. That is, this knowledge of interrelationships among components may enhance the monitoring function, and assist in enhancing corporate governance quality.

The next section of the paper reviews the description and discussion of the associations among the five COSO components contained in the COSO (1992) report as well as relevant literature to develop hypotheses for empirical testing. Subsequent sections discuss the research method, results and discussion, and conclusion. 


\section{Relationships among COSO Components and Hypotheses Development}

COSOs described the broad application of internal control within organisations through its statement that internal control represents "a process, effected by an entity's board of directors, management and other personnel, designed to provide reasonable assurance regarding the achievement of objectives" (COSO, 1992, p. 3) ${ }^{4}$. Conceptually, COSO's five components of internal control represent a set of components that have a foundation based on the control environment. Figure 1 illustrates the relationships among the five components of COSO (1992) and the arrows are an interpretation of the discussion in Chapters 1 to 6 of the COSO (1992) report. The intention of this section is to integrate the discussion in these chapters with any relevant research literature that considered the associations among these components.

Figure 1 illustrates COSO's (1992) suggestion about how the overall internal control system may be managed. First, an ethical control environment enhances risk assessment, and subsequently, control activities, which are then monitored. Notably, the quality of information and communication within the organisation influences the effectiveness of all of these components. Monitoring (through the internal audit function) operates as a feedback mechanism that may require enhancements to the quality of control activities. That is, the monitoring (internal audit) function assesses and reports (communicates) the effectiveness of the control activities, and then subsequently suggests corrections to the control activities.

\section{Figure 1 The COSO Framework's Five Internal Control Components}

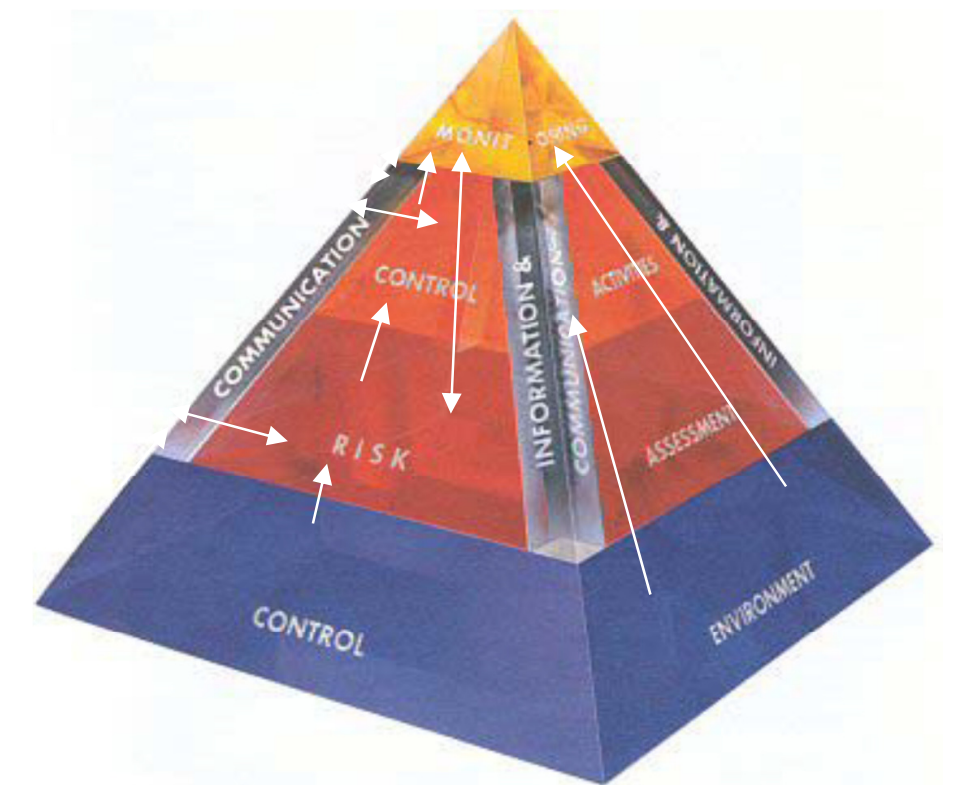

Source: Exhibit 1 Internal Control Components (COSO report, 1992, p. 17)

Directional linkages $\longrightarrow$ = One way; $\longleftrightarrow=$ Two way (reciprocal/looped) 4 Such objectives are categorised into (1) the effectiveness and efficiency of operations, (2) the reliability of
financial reporting, or (3) the compliance of applicable laws and regulations (COSO, 1992, p. 3) 


\section{Associations between Control Environment and other COSO components}

The control environment comprises seven factors identified in COSO $(1992$, which form the foundation component for the other four components in Figure $1 .^{5}$ Notably, the majority of the items within each of the seven factors in the COSO Report have some form of either integrity or ethical value basis that allow for the provision and communication of moral guidance. For example, human resource policies and practices are developed based on the entity's code of conduct or other behavioural guidelines. Hence, Control Environment may also be considered to be the ethical environment.

Within an ethical control environment, COSO (1992) indicates that information and communication is the system by which organisational objectives are managed for risk, internal controls are developed and maintained and monitored for effectiveness through the internal audit function. COSO (1992, p. 23) states that control environment is "...the foundation for all other components of internal control" and that effectively controlled organisations strive to have competent people with integrity and control-consciousness to set the "tone at the top" (p. 23). In Australia, the ethical control responsibility is not limited to top management through the recognition of the significant role of middle management as a component of companies' governance systems (duPlessis et al, 2015). Therefore, this section will discuss research that has examined the associations between control environment and the other four (COSO) components.

\section{Control Environment and Information and Communication}

Moeller (2007) suggests that because the control environment is foundational to the internal control framework, it may influence the characteristics and processes of information and communication within an organisation. Companies with sophisticated performance measurement systems have, within their systems, a function that informs managers of expected goals, and which communicates certain messages about organisational expectations. For example, evidence of unethical companies using measurement systems to place a great deal of pressure on employees to achieve unrealistic goals has been associated with aggressive accounting techniques, earnings management and fraud (Krishnan, 2003; Healy \& Palepu, 2003; Dechow \& Skinner, 2000; Kalbers, 2009). COSO's (1992) Control Environment factor of "Integrity and ethical values" warns of the dangers of focusing on short-term profits at any cost (e.g., "high-pressure sales tactics, ruthlessness in negotiations or implicit offers of kickbacks", p. 24). Such corporate actions may evoke reactions that have detrimental effects to the organisation. Similarly, "management's philosophy and operating style" requires examination of attitudes toward financial reporting and conservative or aggressive selection of accounting principles.

5 These seven factors identified in the COSO report (pp. 31-32) are (1) Integrity and ethics values regarding acceptable business practices, ethical and moral behaviour, (2) Commitment to competence of the employee appointed to a position (i.e., the employee needs to possess the knowledge and skills to perform the required functions adequately, (3) Good corporate governance of the board of directors and audit committee, (4) Management's philosophy and operating style, which involves accepted level of risk tolerance, frequency of senior staff interacting with operating management, and an ethical and good moral attitude to financial reporting accountability and compliance, (6)Assignment of authority and responsibility to an appropriate number of people with requisite skill level for the situation, and (7) Human resource policies and practices for hiring, training, promoting, and compensating employees that are related to the entity's code of conduct and other behavioural guidelines. 
To build core values and integrity within an organisation requires mutual respect and ethical behaviour as the basis of the working relationship that is conducted with a collaborated focus and emphasis on open communication (Young, 2004; Kayes, Stirling, \& Nielsen, 2007). According to Kayes et al. (2007), a culture of integrity as well as new ethical guidelines and procedures must commence with top management communicating these facts throughout the organisation. They also argue that employees must be provided with a communication structure and a feedback mechanism that provide clear channels for employees and management to discuss problems.

\section{Control Environment and risk assessment}

Risk assessment is no longer viewed from the narrow fraud perspective but is now broader to include business risks, which include environmental and other corporate governance and social responsibility risks (Stringer \& Carey, 2002; Johnstone, Li, \& Rupley 2011). Johnstone et al. (2011, p. 339) notes that the COSO report (1992, p. 26) includes in the Control Environment factor "Board of Directors or Audit Committee", which recognises ethical environment "is integral in mitigating risk...". Additionally, the COSO report (1992, p. 23) states that control environment is "...the foundation for all other components of internal control" and that effectively controlled organisations strive to have competent people with integrity and controlconsciousness to set the "tone at the top" (p. 23).

Again, Moeller (2007) suggests that the control environment may influence the scope and degree of risk assessment because it is the underpinning of the internal control framework. Furthermore, Johnstone et al. (2011) found that ethical characteristics of top management act as the key role for the remediation of internal control weaknesses. Consistent with this suggestion, Chtioui and Thiéry-Dubuisson (2011) dissect controls into formal controls and informal controls within an organisation. They include ethical culture in their description of the informal aspects of control environment, which incorporate characteristics of ethical culture identified by COSO $(1992)^{6}$. Therefore, if ethical attitudes and values of senior management act as an informal control, it could be expected to find a greater adherence to internal control systems if highly ethical behaviours developed among employees (Weaver, Trevino \& Cochran, 1999a; 1999b).

\section{Control Environment and control activities}

D'Aquila and Bean (2003) suggest that the foundation for the reliability of financial reports is based on the 'tone at the top' of an organisation. The reliability of financial reports is considered by regulators and the accounting profession to be affected by the quality of an organisation's control activity, which appears to be the impetus for the Sarbanes Oxley legislation requiring directors to make declarations about their organisation's control activities.

COSO (1992, p. 17) identified control environment as providing "...an atmosphere in which people conduct their activities and... responsibilities". The Control Environment, which forms part of the organisational culture, or 'tone at the top', was found to have a direct impact on the

6 Commitment to integrity and ethical values, a board of directors that demonstrates true independence of management and that hold individuals accountable for their internal control responsibilities are the characteristics of ethical culture identified by COSO (1992) and by Chtioui and Thiéry-Dubuisson (2011). 
control activities (Rae, et al, 2008). Their finding suggests that the quality and effectiveness of the control activities may be influenced by the ethical nature of the control environment within an organisation. This result is consistent with the comments in COSO (1992, p. 63) that "all personnel, particularly those with important operating and financial management responsibility, need to receive a clear message from top management that internal control responsibilities muse be taken seriously". Also, employees' internalising integrity and ethical values may mitigate the risk of fraud, and are more likely to adhere to control activities (Michelman \& Waldrup, 2008; Chtioui \& Thiéry-Dubuisson, 2011).

Further, the control environment influence on control activities that are implemented has been suggested by Moeller (2007) because the control environment is fundamental to the internal control framework. Also, Johnstone et al. (2011) found that ethical characteristics of top management act as the key role for the remediation of internal control weaknesses. Consistent with this suggestion, Chtioui and Thiéry-Dubuisson (2011) dissect controls into formal controls and informal controls within an organisation. They described the informal aspects of control environment, which include ethical culture such as those identified by COSO (1992) as commitment to integrity and ethical values, a board of directors that demonstrates true independence of management and that hold individuals accountable for their internal control responsibilities. Therefore, if ethical attitudes and values of senior management act as an informal control, it could be expected to find a greater adherence to control activities if highly ethical behaviours are developed among employees (Weaver, Trevino \& Cochran, 1999a; 1999b).

\section{Control Environment and monitoring activities}

COSOs "Organizational Structure" factor frames the organisational activities that meet the objectives that have been planned, controlled and monitored. Thus, monitoring is an important procedure that evaluates how well the organisational activities, and particularly the control activities, have met the organisation's objectives.

An awareness of the organisation's integrity and ethical values reinforces the accountability culture for employees, which is reflected in the extent of monitoring activities (Stringer \& Carey, 2002). Engagement and accountability of employees, within their organisation's control environment is expected to result in greater monitoring effectiveness (Michelman \& Waldrup, 2008).

Based on the above discussion, the following hypothesis is presented:

H1: There are positive associations between control environment and (a) information and communication, (b) risk assessment, (c) monitoring activity, and (d) internal control activity

\section{Associations between Information and communication and other COSO components}

Management's ability to make appropriate decisions in managing and controlling the entity's activities is influenced by the quality of information. The characteristics of information quality include appropriate information that is timely, current, accurate, and accessible (COSO Report, 
1992, p. 62). Communication of information by personnel needs a means of communicating significant information and receiving information feedback (COSO Report, 1992, p. 65). Information and communication of internal and external information is essential to capture accurately and communicate information in a form and within a timeframe that enables members to complete the activities for which they are responsible. Effective communication also must occur in a broader sense, flowing down, across and up the organisation (Simmons, 1997b). The linkages proposed in COSO's internal control framework model indicate how an organisation's communication would work effectively across departments.

When operational staff and management have a mutual understanding of what is to be accomplished, and the extent to which that accomplishment is sufficient, it is an indication of high quality information and communication. Therefore, the quality of the organisation's information and communication has an impact on the quality of framing the objectives for risk assessment, and also provides an indication of how effectively the internal control activities are monitored. For example, accurate and timely information and communication about the scope and adequacy of the internal control activities will allow more effective risk assessment, and evaluation of whether the control activities are deemed sufficient by the internal auditor or the audit committee through monitoring activities.

\section{Information and communication and risk assessment}

The COSO report (1992, p. 69) has stated that the openness and accuracy characteristics of information, as well as the quality of the communication and feedback processes, determine the value of the information within the organisation's internal control system because high quality information helps staff and management to have a mutual, as well as clear, understanding of what is to be accomplished. Vîlsănoiu and Serban (2010) also state that the timeliness and accuracy of information is central to effective information and communication.

The quality of information that is communicated is an important determinant of the effectiveness of the organisation's risk assessment (Zablow, 2006; Dai, 2011). Thus, the accuracy of in-house information as well as the effectiveness of the communication process is associated with the effectiveness of an organisation's risk assessment. Consequently, it is expected that there is an association between the quality of the information as well as effective communication (such as its accuracy, openness, structure and processes) and risk assessment. Also, when there is a need for a greater degree of management of the identified risks, it is likely to require a greater need for information to evaluate whether the risks are being managed effectively within the organisation's risk appetite. Furthermore, this open and accurate information would need to flow freely through the information system where it may enhance the communication processes of staff involved in risk assessment activities (Ford, 2006; Hutt, Stafford, Walker \& Reingen, 2000).

Therefore, the effective communication of internal and external relevant information is essential for organisational members to carry out their responsibilities, such as risk assessment. This information must be identified, captured accurately and communicated in a form and timeframe that enables members to complete the activities for which they are responsible. 


\section{Information and communication and control activities}

The structure of an organisation's internal communication is considered critical for the success of control activities (Kayes et al., 2007; Michelman \& Waldrup, 2008). Johnstone et al. (2011) explained that effective information and communication should increase the quality of control activities because staff members are made aware of the status of control activities. Similarly, COSO (1992, p. 18) states that having accurate, timely information available to the right people is essential to effecting control activities. Also, information should be customised to allow the control activities to function.

\section{Information and communication and monitoring activities}

Simmons (1997a, p. 69) argues that the information and communication component should be linked to the extent of the monitoring activities component of COSO internal control. He argued that the information and communication component enables people to carry out their responsibilities, which include identifying and capturing information that would influence decisions about the extent of the necessary monitoring activities. Consequently, companies may find value in developing information and communication processes whereby employees will not hesitate to report any observed deficiencies in the control system to the monitoring function for evaluation. Such information and communication processes that enable access to the monitoring function is expected to enhance the quality of an organisation's internal control system (Ratnatunga \& Alam, 2011). Also, sufficient and timely information allows monitoring of management's objectives and strategies (COSO, p. 31).

Information and communication is considered a characteristic that is pervasive throughout companies (Moeller, 2007). Consequently, the following hypothesis is proposed related to the association between information and communication, risk assessment, control activities, and monitoring activities based on the discussion under the three preceding sub-sections for the information and communication component.

H2: There are positive associations between information and communication and (a) risk assessment, (b) internal control activity, and (c) monitoring activity.

\section{Associations between risk assessment and other COSO components}

First, the discussion will focus on the association between the risk assessment and control activities. Second, the analysis will address literature related to the association between risk assessment and monitoring activities. Risk assessment activities involve identifying and analysing relevant risks, both internal and external to the organisation.

\section{Risk assessment and control activities}

COSO describes categories of objectives for which internal controls may be developed in its Chapter 3 on Risk Assessment. For example, an operational objective may be to have controls over physical assets to prevent theft or loss. Financial Reporting objectives may require controls to prevent fraudulent reporting of financial reports. Internal control focuses on developing 
consistent objectives and reporting on key success factors. It is recognised in the COSO Report (1992, p. 33) that although risk assessment is not an internal control component, it is a prerequisite to and enabler of internal control activities. That is, the association between risk assessment and control activities are considered together because "...management establishes activity-level objectives and mechanisms for identifying and analyzing risks related to their achievement, and develops the necessary actions and control activities to address those risks." (COSO report 1992, p. 130)

Research has identified evidence that risk assessment approaches adopted by companies are associated with their control activities (Stringer \& Carey, 2002; Goodwin-Stewart \& Kent, 2006; Michelman \& Waldrup, 2008). For example, many risk management policies and standards may subsequently form part of the control activities. Jokipii (2010) found relationships between risk assessment and control activities. Therefore, identifying these critical areas where internal controls are needed is expected to lead to remedies that enhance internal control quality.

\section{Risk assessment and monitoring activities}

COSO (1992) notes under Risk Assessment Chapter 3 that an entity should have reasonable assurance that the organisation is achieving certain objectives. Many techniques used to identify risks were developed by internal and external auditors (COSO, 1992). Although monitors (such as internal auditors) are familiar with evaluating financial reporting transactions, there is an increasing need for monitors to develop strengths in evaluating and "responding to all risks" (Kinney, 2003, p. 144). As an organisation expands the scope of its risk assessment and management, there will be an increased need to expand the role of the monitoring function so that it can effectively monitor, evaluate and refine the way in which risks are managed (Michelman and Waldrup, 2008). Such monitors play a key role in auditing control activities because many control activities may have arisen as a result of an expanded risk assessment and management process. Consequently, the internal audit function is well placed to refine control activities that reflect the degree of risk assessment required by senior management for quality governance within the organisation's risk appetite.

The awareness among employees about the various types of risks faced by their organisation, (and how such risks may be interconnected) as well as the risk mitigation strategies put in place by management is expected to be greater in companies with a wide risk assessment agenda than those with a narrow risk assessment agenda. Lindow and Race (2002) argue that, as a firm widens its array of risk assessment activities, there will be greater demand for the monitoring function to assist in administering and monitoring many of these risk assessment activities.

Based on the above discussion, the following hypothesis is presented:

\section{H3: There are positive associations between the risk assessment and (a) control activities and (b) monitoring activities.}




\section{The Association between Control Activities and Monitoring}

Control activities are the policies and procedures that occur throughout the organisation, at all levels and in all functions, and help ensure that necessary actions are taken to address risks to achievement of the entity's objectives (COSO, 1992, p. 3). Therefore, the implementation of these control activities is critical and needs to be monitored over time to ensure the control activities are operating effectively. For example, circumstances present when the control activities were designed originally may change and management needs to determine whether the control activities are still relevant. Monitoring ensures that control activities are operating effectively.(COSO, P. 69).

In summary, COSO asserts that monitoring ensures that control activities operate effectively, and thus, the fourth hypothesis for the study is as follows:

\section{H4: There is a direct and positive association between control activity and monitoring.}

\section{$3 \quad$ Research Method}

A questionnaire survey, a letter of invitation, and two reply paid envelopes ${ }^{7}$ were mailed to financial controllers or chief accountants of a randomly selected sample of 450 medium to large publicly listed or private companies across Australia. ${ }^{8}$ There are three reasons for targeting financial controllers as the participants for this study to gather information to examine the proposed associations among the five COSO components. First, they should have a good understanding of the quality of control activities because of their senior position. Second, they should be aware of any control weaknesses or malfunctions of control activities because they are often actively involved in the oversight of any system reviews and changes. Third, they represent the 'tone in the middle' identified as an emerging issue in corporate governance, (Banerjee and Gupte, 2015).

Literature discussed in the hypothesis section was used to identify statement items and these items were adapted to design a questionnaire. It is assumed the invitation was received by 306 companies, which represents the final sample frame, because 144 letters were returned unclaimed. A total of 69 (53 males and 8 females) usable responses were received (20\% usable

\footnotetext{
7 These two envelopes were provided for the respondents to return their completed questionnaire separately from their request to receive a copy of the results, which would be activated by the post card sent in the other envelope. The post card also enabled a follow up procedure to be completed while reinforcing the anonymity of the respondents. Ethical clearance for this research was obtained from the University's Social Sciences, Business, and Arts Ethics Sub Committee. A letter was forwarded to each firm, with a declaration that the questionnaire was given ethical clearance by the University's sub-committee, along with the researcher and supervisor's contact details. Each letter invited respondent's participation to complete the questionnaire while allowing each participant to remain anonymous.

8 Kompass Australia and Who's Who of Business databases provided details of medium to large-sized companies with revenues greater than $\$ 20$ million per annum and which employ more than 100 employees. Company size or type is not considered an issue for this study because COSO $(1992,2011)$ state that the framework was intended to apply to all companies because the seventeen principles underlying the five components that were included in COSO (2011, p. 20) "are just as applicable for smaller entities as for larger ones" and regardless of whether the entity is publicly listed or a private company.
} 
responses). ${ }^{9}$ Thirty-six (36) respondents $(57.4 \%)$ were from large-sized companies (i.e. 250 employees and above) and 25 respondents (42.6\%) from medium-sized companies with 100 to 250 employees. A t-test produced a non-significant result between these two company size groups for all the items that loaded onto the five COSO component factors for this study. 4 Variable Measurement Model

The COSO five-component latent variables have been operationalised using existing measurement instruments. Schumaker and Lomax (1996) recommended the two-stage process, which has been adopted by this study. Stage one of the process requires separate measurement models to be conducted for each latent variable. The goodness of fit for each confirmatory factor analysis used for this stage appropriate measurement models (and subsequent Stage Two structural equation model) will use benchmarks established by identified prior studies. ${ }^{10}$

\section{Control Environment}

The control environment comprises seven factors identified in COSO (1992) and these factors form the foundation component for the other four components in Figure $1 .^{11}$ The majority of the items within each of the seven factors identified in COSO report (1992) have some form of either integrity or ethical value basis. Therefore, control environment may be considered to be the ethical environment. Control environment was measured using a five-item, five-point Likert-type scale as developed by Hunt, Wood and Chonko (1989) and used previously (e.g., Rae et al. 2008).

The results for the Cronbach Alpha evaluating the internal reliability of the ethical scale show a relatively strong result at $0.696 .{ }^{12}$ Further, a factor analysis revealed a one dimensional scale for the five-item control environment scale $(\mathrm{KMO}=.704$; Sig $=0.000)$ and provided a Z-

9 Three of the returned questionnaires were discarded due to incomplete responses, while five of the questionnaires were discarded because the company had less than 100 employees.

10 The confirmatory factor analysis was conducted using structural equation modelling within the AMOS statistical software programme. The following statistics and referenced literature are the basis for evaluating the goodnessof-fit measurement and SEM models $\{\mathrm{P}$ (Probability) is the desired result because a Non-significant probability cannot reject the goodness-of-fit of the hypothesised model [Byrne, 2001], CMIN/DF Ratio of $<2$ indicates a good-fitting model [Tabachnick \& Fidell, 2001] , SRMR (Standardised Root Mean Squared Residual) that is < .05 represents a well-fitting model [Byrne, 2001], GFI (Goodness-of-Fit Index) required value of $>.9$ for each of these indices [Page \& Meyer, 2000] ; Tabachnick \& Fidell, 2001], AGFI (Adjusted Goodness-of-Fit Index), NFI (Normal Fit Index), CFI (Comparative Fit Index) Required value of between $>.9$ [Tabachnick \& Fidell, 2001] and $\geq .95$ [Hu \& Bentler, 1999] for each of these indices, and RMSEA (Root Mean Square Error of Approximation) is one of the most informative criteria with $\leq .08$ as the desired value of RMSEA [Hu \& Bentler, 1999; Tabachnick \& Fidell, 2001]\}.

11 These seven factors identified in the COSO report (pp. 31-32) are (1) Integrity and ethics values regarding acceptable business practices, ethical and moral behaviour, (2) Commitment to competence of the employee appointed to a position (i.e., the employee needs to possess the knowledge and skills to perform the required functions adequately) , (3) Good corporate governance of the board of directors and audit committee, (4) Management's philosophy and operating style, which involves accepted level of risk tolerance, frequency of senior staff interacting with operating management, and an ethical and good moral attitude to financial reporting accountability and compliance, (6)Assignment of authority and responsibility to an appropriate number of people with requisite skill level for the situation, and (7) Human resource policies and practices for hiring, training, promoting, and compensating employees that are related to the entity's code of conduct and other behavioural guidelines.

12 Varying levels of this alpha coefficient have been used in literature but Nunnally and Berstein (1994) suggest 0.70 to be an acceptable reliability coefficient level. However, Cronbach Alphas of between 0.60 and 0.70 have been considered acceptable because "These reliability values were comfortably above the lower limits of acceptability, generally considered to be around .50 to .60 (Nunnally, 1978)" [Govindarajan, 1988, p. 839]. 
score, which was supported by the confirmatory factor analysis statistics (CMIN/DF $=1.133$, $\mathrm{SRMR}=0.0374, \mathrm{GFI}=0.983, \mathrm{AGFI}=0.914, \mathrm{NFI}=0.957, \mathrm{CFI}=0.994, \mathrm{RMSEA}=0.047)$.

\section{Information and Communication}

The discussion under the section Information and Communication and other COSO components provides evidence to illustrate the complexity of the communication process. The evidence provided under that section supports the suggestion that COSO's information and communication component should be investigated as a multidimensional component. COSO describes salient information characteristics as timely, current, accurate and accessible (p. 62). These characteristics are considered most important for information and communication processes because they enable the circulation of significant information and facilitate information feedback (COSO Report, 1992, pp. 62, 65). Four dimensions are used to operationalise COSO's information and communication component for this study using existing measurement instruments; (1) information openness, (2) information accuracy, (3) communication processes, and (4) information feedback flow.

\section{Information openness and information accuracy}

To measure the openness of the exchange of information and the accuracy of information exchange, the current study has chosen to adopt a survey instrument that captures data about the dimensions related to openness and accuracy as identified by Downs (1988). O'Reilly and Roberts (1976) have developed a survey instrument to capture data about the extent to which information is openly shared throughout the organisation.

The 'information openness' construct was factor analysed. The results revealed a significant result $(\mathrm{KMO}=.718 ; \mathrm{Sig}=0.000)$ while a high Cronbach Alpha $(\alpha=0.791)$ supported a relatively strong internal reliability for the 'information openness' scale. The confirmatory factor analysis supports the existence of the 'information openness' construct $(\mathrm{CMIN} / \mathrm{DF}=$ 0.098, SRMR $=0.0108$, GFI $=0.999$, AGFI $=0.990$, NFI $=0.998$, CFI $=1.000$, RMSEA $=$ 0.000). Therefore the $\mathrm{Z}$-score for the nine-item survey instrument has been used in the analysis.

Similarly, the other dimension related to information sharing was included in the factor analysis, which was 'information accuracy'. The results for 'information accuracy' showed a significant result $(\mathrm{KMO}=.835 ; \mathrm{Sig}=0.000)$, with a high Cronbach Alpha $(\alpha=0.882)$. The results for the Cronbach Alpha support a strong degree of internal reliability for 'information accuracy'. The confirmatory factor analysis results $(\mathrm{CMIN} / \mathrm{DF}=0.242$, $\mathrm{SRMR}=0.0111, \mathrm{GFI}=0.994, \mathrm{AGFI}=$ $0.976, \mathrm{NFI}=0.994, \mathrm{CFI}=1.000, \mathrm{RMSEA}=0.000$ ) support the existence of 'information accuracy' as a factor to be used in the analysis.

\section{Communication processes}

To measure the communication processes, a survey instrument was adopted that captures data about the dimensions related to how well the organisation's communication process may facilitate organisational learning, as identified by Downs (1988). A survey instrument was 
developed by Morrison and Terziovski, (2001) to examine how the information systems support the association between management practices and learning outcomes.

The factor analysis of the 'Communication processes' construct revealed a significant result $(\mathrm{KMO}=.846 ; \mathrm{Sig}=0.000)$. The test for internal reliability results show a high Cronbach Alpha $(\alpha=0.895$ ) supports a strong level of internal reliability for the communication processes construct. The results of the confirmatory factor analysis $(\mathrm{CMIN} / \mathrm{DF}=0.582, \mathrm{SRMR}=0.0200$, $\mathrm{GFI}=0.986, \mathrm{AGFI}=0.947, \mathrm{NFI}=0.987, \mathrm{CFI}=1.000, \mathrm{RMSEA}=0.000)$ support the inclusion of 'communication processes' as a dimension of the information and communication component.

\section{Information feedback flow}

A survey instrument, developed by Morrison and Terziovski (2001), examined how the information systems support organisational outcomes by evaluating the quality of the organisation's information flow. Using Morrison and Terziovski's (2001) survey instrument, the feedback flow will be measured to determine whether it flows upwards, downwards, as well as across the various departments throughout the organisation.

The results for the factor analysis on information feedback flow provided significant results $(\mathrm{KMO}=.720 ; \mathrm{Sig}=0.000)$. Also, the results of the test for internal reliability reveal a quite high Cronbach Alpha $(\alpha=0.808)$, which supports a strong internal reliability for the 'information feedback flow' construct. As with the other constructs, the results for the confirmatory factor analysis $(\mathrm{CMIN} / \mathrm{DF}=0.168, \mathrm{SRMR}=0.0101, \mathrm{GFI}=0.999, \mathrm{AGFI}=0.986, \mathrm{NFI}=0.998, \mathrm{CFI}=$ 1.000 , RMSEA $=0.000$ ) provide support for the information feedback flow dimension. Therefore the Z-score for information feedback flow construct has been used in the analysis.

\section{Risk Assessment}

Risk assessment was measured by asking each respondent to rate the extent to which four items of risk assessment have been adopted by a firm. These four items were adapted from Fatemi and Glaum (2000) and have been used in prior studies (e.g., Rae et al. 2008). Each item relates to a specific area that is likely to be included within a firm's risk profile, and managed to varying degrees. The scope, as well as the degree (or systematic nature) of management of these risks, then forms the basis for the risk assessment activities undertaken by the organisation. The measures for the current study include the management of financial, environmental, technological, and operational risks, which are measured on a five-point Likert-type scale.

A factor analysis of the risk assessment construct produced a significant result for the single dimensional construct $(\mathrm{KMO}=0.979$; Sig $=0.000)$. In addition, a high Cronbach Alpha $(\alpha=$ 0.858) supported a strong internal reliability for the risk assessment scale. The results for the confirmatory factor analysis of the risk assessment construct $(\mathrm{CMIN} / \mathrm{DF}=1.465, \mathrm{SRMR}=$ $0.0271, \mathrm{GFI}=0.977, \mathrm{AGFI}=0.883, \mathrm{NFI}=0.974, \mathrm{CFI}=0.991, \mathrm{RMSEA}=0.088)$ support this construct as a factor. Therefore the Z-score for the risk assessment construct has been used in the analysis. 


\section{Control Activities}

The 'Control activities' construct was assessed based on a seven-item scale, whereby the items were adapted from the 'Small Business Sample' Section of CPA Australia's Small Business survey (CPA Australia, 2003). Each participant was required to rate the firm's internal control strength, using a seven-point Likert-type scale anchored at both ends with $1=$ very poor to $7=$ very good, in seven key areas. These include 'cash management', 'bank accounts', 'physical assets', 'purchasing and accounts payable', 'sales', 'employee recruitment' and 'payroll'. These items have been used previously by Rae et al. (2008). Data analyses were based on the Z-score of a factor analysis for the seven-item $(\mathrm{KMO}=.869 ; \mathrm{Sig}=0.000)$. A confirmatory factor analysis produced goodness of fit indices $(\mathrm{CMIN} / \mathrm{DF}=0.814, \mathrm{SRMR}=0.0376, \mathrm{GFI}=0.949$, $\mathrm{AGFI}=0.884, \mathrm{NFI}=0.962, \mathrm{CFI}=1.0000, \mathrm{RMSEA}=0.0000)$ that support this measurement model. The internal reliability for these seven-items was also strong with the Cronbach Alpha being 0.912 .

The questionnaire also asked an additional question on the perceived quality of the internal controls overall so as to gain an assessment of the respondent's overall judgement of the strength of the internal controls. A bivariate correlation analysis between the average score of the sevenitem measure and the overall rating indicates a significant and strong correlation exists.

\section{Monitoring Activities}

The extent of monitoring activities was measured by asking each respondent about the extent to which their organisation, in the last financial year, undertook certain internal audit activities. Four questions relating to the main areas of internal audit were provided for the respondent to rate. These four questions were adapted from Simmons (2008) regarding the scope of a firm's internal auditing. Three of the questions relate directly to three basic audit objectives originating from Guideline 300.06 of the Standards for the Professional Practice of Internal Auditing (the SPPIA). These audit objectives are: (1) to determine whether controls provide reasonable assurance of effective and efficient operations, (2) to determine whether controls provide reasonable assurance as to the reliability of financial data and reports; and (3) to determine whether controls provide reasonable assurance of compliance with laws and regulations. The fourth question, adapted from Simmons (2008), relates to whether the internal audit function undertakes investigation related to strategic issues. An eight-point scale was provided with 0 being 'none', 1 representing to 'a very small extent' and 7 signifying 'a very large extent'.

Data analyses were based on the factor analysis Z-score for the Monitoring four-item instrument $(\mathrm{KMO}=.760 ; \mathrm{Sig}=0.000)$. The confirmatory factor analysis produced goodness of fit indices $(\mathrm{CMIN} / \mathrm{DF}=0.834, \mathrm{SRMR}=0.0082, \mathrm{GFI}=0.993, \mathrm{AGFI}=0.931, \mathrm{NFI}=0.995, \mathrm{CFI}=1.000$, RMSEA $=0.000$ ) which provide support for this measurement model. The internal reliability measured for these four items was strong with the Cronbach Alpha being 0.896. 


\section{$5 \quad$ Results}

\section{Statistical Analyses}

Structural equation modelling (SEM) was used to test the developed hypotheses. SEM was considered to be the preferred method of analysis because it allows multiple associations to be the analysed simultaneously, provides measures of overall model fit, and explains the significance of associations between variables (Kline, 1998; Baines \& Langfield-Smith, 2003). The advantages of SEM over path analysis (Viator, 2001) include the three functions mentioned above, and account for the effects of measurement error in multi-item variables.

The results for each confirmatory factor analysis are reported under the discussion for each variable earlier in this paper under section 4.0 (Variable Measurement). Stage two of the process, recommended by Schumaker and Lomax (1996) involves constructing the structural model and the results, which are reported in Table 1, and the significant SEM structural paths discussed for their respective hypothesis.

\section{Results of Hypotheses}

The goodness of fit statistics $(\mathrm{P}=0.586, \mathrm{CMIN} / \mathrm{DF}=0.535, \mathrm{SRMR}=0.0218, \mathrm{GFI}=0.996$, AGFI $=0.921, \mathrm{NFI}=0.994, \mathrm{CFI}=1.000, \mathrm{RMSEA}=0.000$ ) support a robust initial SEM for all the associations proposed in $\mathrm{H}_{1}, \mathrm{H}_{2}, \mathrm{H}_{3}$ and $\mathrm{H}_{4}$. The maximum likelihood estimates and indices for the SEM Model structural path are summarised following the discussion for the specific association and in Table 1.

There are ten significant SEM model structural paths, which are identified in Figure 1. These significant paths represent direct associations between the COSO component variables for this study, and are included in the four hypotheses. Hypothesis One relates to four separate associations between control environment and the other four components of COSO. The results do not support any significant direct association between control environment and risk assessment in Hypothesis One (b), control environment and control activities in Hypothesis One (c), or control environment and monitoring Hypothesis One (d). However, Table 1 does show a significant direct association between control environment and three of the four dimensions of the information and communication variable [Hypothesis One (a)]. Three significant paths are the association between control environment and information openness $(\mathrm{CR}=3.465 ; \mathrm{P}<0.001)$, the association between control environment and information accuracy $(\mathrm{CR}=3.928 ; \mathrm{P}<0.001)$, and the association between control environment and communication processes $(\mathrm{CR}=52.029 ; \mathrm{P}$ $<0.001)$. There was no significant association between control environment and information feedback flow. Therefore, the SEM results provide partial support for Hypothesis One (a) but do not support Hypothesis One (b), Hypothesis One (c), or Hypothesis One (d). 


\begin{tabular}{|c|c|c|c|c|c|c|}
\hline \multicolumn{7}{|c|}{$\begin{array}{cc}\text { Table 1: Maximum Likelihood Estimates: SEM M } \\
\end{array}$} \\
\hline \multicolumn{3}{|c|}{ Regression Weights } & \multirow{2}{*}{$\begin{array}{r}\text { Estimate } \\
.408\end{array}$} & \multirow{2}{*}{$\begin{array}{l}\text { S.E. } \\
.118\end{array}$} & \multirow{2}{*}{$\begin{array}{l}\text { C.R } \\
3.465\end{array}$} & \multirow{2}{*}{$\begin{array}{l}\mathbf{P} \\
\text { *** }\end{array}$} \\
\hline Information Openness & $<---$ & Control Environment & & & & \\
\hline Information Accuracy & $<---$ & Control Environment & .452 & .115 & 3.928 & $* * *$ \\
\hline Communication Processes & $<---$ & Control Environment & .239 & .109 & 2.190 & .03 \\
\hline Info Feedback Flow & $<---$ & Control Environment & .151 & .112 & 1.348 & .18 \\
\hline Scope Risk assessment & $<---$ & Control Environment & .094 & .131 & .718 & .47 \\
\hline Control Activities & $<---$ & Control Environment & .029 & .147 & .195 & .85 \\
\hline Monitoring & $<---$ & Control Environment & .098 & .119 & .828 & .41 \\
\hline Scope Risk assessment & $<---$ & Information Accuracy & -.194 & .129 & -1.498 & .13 \\
\hline Scope Risk assessment & $<---$ & Information Openness & -.236 & .144 & -1.645 & .10 \\
\hline Scope Risk assessment & $<---$ & Communication Processes & .319 & .168 & 1.900 & .05 \\
\hline Scope Risk assessment & $<---$ & Information Feedback Flow & .457 & .163 & 2.803 & $* *$ \\
\hline Control Activities & $<---$ & Information Accuracy & .171 & .135 & 1.264 & .21 \\
\hline Control Activities & $<---$ & Information Openness & .182 & .160 & 1.138 & .26 \\
\hline Control Activities & $<---$ & Communication Processes & -.150 & .182 & -.822 & .41 \\
\hline Control Activities & $<---$ & Information Feedback Flow & .072 & .165 & .434 & .66 \\
\hline Monitoring & $<---$ & Information Accuracy & -.067 & .120 & -.560 & .58 \\
\hline Monitoring & $<---$ & Information Openness & .027 & .134 & -.204 & .84 \\
\hline Monitoring & $<---$ & Communication Processes & .220 & .157 & 1.400 & .16 \\
\hline Monitoring & $<---$ & Information Feedback Flow & -.033 & .156 & .209 & .83 \\
\hline Control Activities & $<---$ & Scope Risk assessment & .317 & .136 & 2.333 & .02 \\
\hline Monitoring & $<---$ & Scope Risk assessment &. .186 & .121 & 1.542 & .123 \\
\hline Monitoring & $<---$ & Control Activities & .490 & .104 & 4.693 & $* * *$ \\
\hline Analysis of Informatio & and $\mathrm{C}$ & nmunication's dimensions & Estimate & S.E. & C.R. & $\mathbf{P}$ \\
\hline Information Feedback Flow & $<---$ & Information Accuracy & .325 & .107 & 3.042 & $* *$ \\
\hline Communication Processes & $<---$ & Information Accuracy & .090 & .104 & .867 & .38 \\
\hline Communication Processes & $<---$ & Information Openness & .528 & .101 & 5.212 & $* * *$ \\
\hline Information Feedback Flow & $<---$ & Information Openness & .405 & .105 & 3.871 & $* * *$ \\
\hline
\end{tabular}

The SEM paths to test the associations of Hypotheses Two for the information and communication variable have been dissected into the four dimensions of information and communication as described in Section 4. The SEM results provide partial support for the association between information and communication and risk assessment, Hypothesis Two (a), but do not support the association between information and communication and control activity, Hypothesis Two (b), or the association between information and communication and monitoring, Hypothesis Two (c). Hypothesis Two (a) is partially supported by two statistically significant direct associations: first, between the path that represents the association of communication and learning processes (a dimension of communication) and risk assessment $(\mathrm{CR}=1.900 ; \mathrm{P}=0.05)$; as well as second, between information feedback flow (another dimension of communication) and risk assessment $(\mathrm{CR}=2.803 ; \mathrm{P}<0.005){ }^{13}$ There were two associations hypothesised in Hypothesis 3 and the results for this hypothesis support only Hypotheses Three (a) for the

13 Hypotheses Two (a) was not fully supported because there were no statistically significant associations found for the two dimensions for Information (information openness and information feedback information accuracy) and and scope of risk assessment. 
association between risk assessment and internal control activities $(\mathrm{CR}=2.333 ; \mathrm{P}=0.02)$. The results do not support Hypotheses Three (b) between risk assessment and monitoring. The statistics support a significant direct association between control activities and monitoring (Critical Ratio $(\mathrm{CR})=4.693 ; \mathrm{P}<0.001)$. Therefore the results provide support for Hypothesis Four.

The results for Hypothesis One (b) do not support any direct relationship between ethical environment and scope of risk assessment as described in COSO Report (1992). However, indirect associations that are identified from the SEM model are between ethical environment and scope of risk assessment mediated by the information and communication in four different series of mediating paths (a) communication processes, (b) information openness together with communication processes, (c) information openness together with information feedback flow, and (d) between information accuracy together with information feedback flow. ${ }^{14}$

One reason for this result is due to the primary SEM only representing a one-way effect whereas some two-way effects, illustrated in Figure 1 for this study, were mentioned in the COSO Report (1992). Therefore, two additional (secondary) SEM analyses were considered necessary to examine the reciprocal associations among the five COSO components. The goodness-of-fit statistics for the first alternative SEM model $(\mathrm{P}=0.333, \mathrm{CMIN} / \mathrm{DF}=0.938, \mathrm{SRMR}=0.0204$, GFI $=0.996$, AGFI $=0.861, \mathrm{NFI}=0.995, \mathrm{CFI}=1.000, \mathrm{RMSEA}=0.000)$ show control environment is directly associated with risk assessment (CR CR 2.258, P $<.05$ ) as well as with both dimensions of information (CR 3.216, $\mathrm{P}<.01$ ). Also, risk assessment is associated with both dimensions of communication (Information feedback flow $=\mathrm{CR} 4.011, \mathrm{P}<.001$; Communications processes $=\mathrm{CR} 3.365, \mathrm{P}<.001)$. However, information and communication is not directly associated with internal control activities and monitoring.

Goodness-of-fit statistics for the second alternative SEM model $(\mathrm{P}=0.605, \mathrm{CMIN} / \mathrm{DF}=0.724$, SRMR $=0.0332$, GFI $=0.981$, AGFI $=0.920$, NFI $=0.972$, CFI $=1.000$, RMSEA $=0.000)$ support a direct association between control activities and monitoring (CR 5.497, P <.001), direct reciprocal associations between monitoring and the communication processes dimension of communication (CR 2.298, $\mathrm{P}=.02$ ) as well as between the communication processes dimension of communication and the information openness dimensions of information (CR 3.822, $\mathrm{P}<$ .001). Also, there is an indirect reciprocal association between the communication processes dimension of communication and the information accuracy dimensions of information that is mediated by the information feedback flow dimension of communication (CR 3.216, P <.01; CR $3.270, \mathrm{P}<.01)$.

14 The results from in the SEM model analysis produced three significant paths among the four dimensions of the information and communication variable. Three significant results are the association between information openness and communication processes ( $C R=5.212 ; P<0.001)$, the association between information openness and information feedback flow $(C R=3.871 ; P<0.001)$, the association between information accuracy and information feedback flow (3.042; $P<0.01)$. 
Figure 2 Direct, Indirect and Reciprocal Associations among COSO components

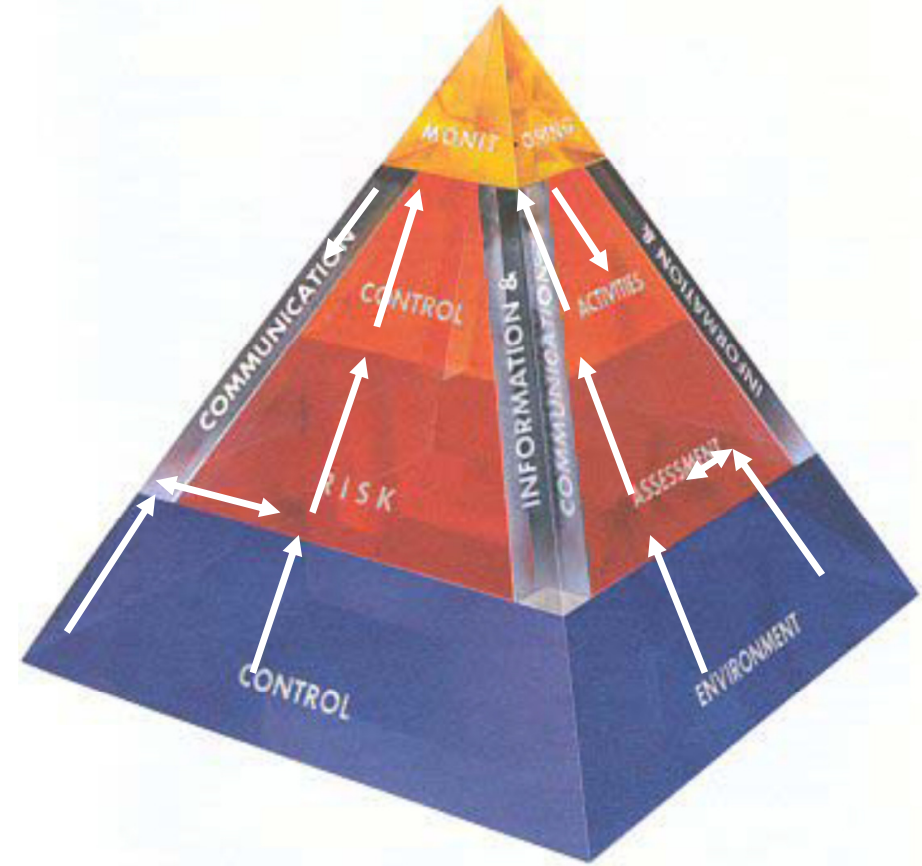

Source: Exhibit 1 Internal Control Components (COSO report, 1992, p. 17)

Directional linkages $\longrightarrow=$ One way; = Two way (reciprocal/looped)

The primary and two alternate SEM significant paths are illustrated in Figure 2. This illustration of the various associations support by SEM results will be the basis for the conclusions, discussion, and limitations in the next section.

First, there is a direct association between control environment and information and communication. Second, information and communication has an association with risk assessment while risk assessment is associated with formulation of control activity policy and procedures. Therefore, control activity policy and procedures need to be monitored to ensure implementation, compliance, and relevance of control activity policy and procedures. Additionally, the first alternative SEM supports an association between control environment and risk assessment as well as between risk assessment and the information and communication component; the latter association being a reciprocal association. Further, the second alternative SEM supports a reciprocal association between monitoring and the information and communication component.

These findings support the importance of not only the control environment component but also information and communication component for risk assessment as well as risk assessment's impact on control activity's policy and procedures. The consequence of these findings highlights the necessity for monitoring these policy and procedures for their implementation, compliance, and relevance. The iterative process seems to occur with the two-way associations between risk assessment and information and communication components as well as between monitoring and information and communication components. These feedback loops would update the currency, accuracy and relevance of information in a timely manner for risk reassessment. The 
reassessment of risk using this information leads to a revision of control activity policy and procedures, which will need continuous monitoring and the iterative process continues. For example, risk assessment may identify new risks, which are reported to internal auditors who develop control activities. These control activities are monitored and the risk officer checks if the controls are effectively mitigating this new risk.

Although the control environment is called the foundational component, there are both direct and indirect (sequential) links with other components. First, there are two separate direct links between control environment and (1) information and communication as well as (2) risk assessment. Second, a link exists between control environment and control activities, which is linked sequentially with monitoring activities. The SEM path can be described as control environment having a link to the information and communication component. The transmission of timely and accurate information to the risk assessment department enables the information to be processed. The results support the conclusion that where middle management perceives the existence of more ethical control environments, organisations also possess information characteristics of greater openness and accuracy, and better communication processes. This is consistent with the findings of Johnstone et al. (2011) that improvements in the control environment are associated with remediation of material weaknesses in the information and communication component.

Information feedback flow and communication processes are associated with a reciprocal flow of accuracy and relevant information for better risk assessment. The dimensions of information and communication follow COSO's (1992) Internal Control - Integrated Framework (ICIF) that a key feature of effective information is its quality, or usefulness to "make appropriate decision in managing and controlling the entity's activities", such as information timeliness, accuracy and accessibility (1992, p. 62). Therefore, communication is essential so that management may keep up to date on risks and major initiatives, because information and communication is essential to assess risks effectively. Risk assessment is associated with control activities, which is subsequently associated with monitoring. Therefore, while the results indicate that there is no direct association between control environment and internal control activities or the monitoring function, they do support that control environment indirectly influences internal control activities and monitoring through greater integrity and respect for the information and communication system by developing an ethical culture.

The first additional SEM shows, specifically, that there are significant direct associations between control environment and two dimensions of information and communication (information accuracy and openness). Its results also support that the association between risk assessment and information and communication has two significant dimensions (communication processes and information feedback flow). It is logical to assume that the risk assessment department will then create new information and update existing information within the information and communication system once they have analysed the assessed risks. Accordingly, risks will be better managed when relevant information is communicated to various members within the organisation. These additional SEM results therefore support a logical association between risk assessment and information and communication that appears to be a cyclical process of continual inputs and outputs. 
These findings are consistent with Simmons (1997b) who argued that effective communication also must occur in a broader sense, flowing down, across and up the organisation Therefore, if an organisation's communication works effectively across departments, then the linkages proposed in COSOs internal control framework model would be plausible. That is, information, because of the ethical nature of the control environment, could be communicated to the risk assessors, who could convert their assessment of the risks involved within the control activities so they can be subject to enhanced monitoring and remedial action, if required (Simmons, 1997b). This result is consistent not only with Vîlsănoiu and Serban (2010) who concluded that risk managers may use control activities to help identify problem areas and monitor progress toward solving any risk related problem, but also Jokipii's (2010) findings that show a significant covariant relationship between control activities and monitoring activities. The links in the first additional SEM model hinge on transparent information and communication, which is the cornerstone of quality corporate governance.

The result of the second additional SEM analysis shows an association between monitoring and information and communication that leads to information openness and accuracy through the communication processes and information feedback flow. Such findings are consistent with prior studies where it is interpreted that monitoring is designed to improve not only the quality of public corporate financial information (Verschoor and Farrell, 1996) but also to assess the effectiveness of control activities and to report to management where and how control activities could be strengthened (Van Peursem, 2004).

The COSO model (replicated in Figure 1) "depicts the dynamism of internal control systems. For example, the assessment of risks not only influences the control activities, but also may highlight a need to reconsider information and communication needs, or the entity's monitoring activities. Thus, internal control is not a serial process, where one component affects only the next. It is a multidirectional iterative process in which almost any component can and will influence another" (COSO, 1990, p. 18). This study's first contribution to the body of knowledge is the findings across the five COSO components that support this description of the dynamic nature of internal control systems. The second contribution of this study is that it produces evidence for the existence of some direct and indirect associations among the COSO components that support the statement in COSO Report (1992) that internal control is not a serial process; that is, one component does not only affect the next component (direct association). The third contribution is where the study's results identify which specific components (information and communication and monitoring activities) support the multidirectional iterative process assertion. The fourth contribution is the identification of only two components with a reciprocal association. This evidence improves the specificity to the statement that "almost any component can and will influence another" (COSO, 1990, p. 18).

This examination of the direct, indirect, and reciprocal associations among the components of internal control systems may assist companies to develop more effective processes within the components of COSO's internal control framework, which may enhance the quality of corporate governance systems. Therefore, both top management and middle management should consider the three (direct, indirect and reciprocal) associations of the COSO components of internal control systems when developing their plan for their audit and conducting their field work. That is, management and the internal audit department should consider identifying the nature of their 
organisation's ethical environment, information and communication, the risk assessment and control activities within their organisation when planning their monitoring activities, which should take into consideration the impact of reciprocal associations between information and communication and risk assessment as well as between monitoring and information and communication and should indicate the nature of the control activities to be undertaken. The evidence from this study that supports the existence of reciprocal associations among the COSO components is consistent with the findings of Imonianna et al (2012) that connections of all activities by an integrated system were essential to ensure information reliability. They concluded that this continuous updating of information will assist in ensuring that the internal control structure provides a foundation to enhance and strengthen the quality of an organisation's corporate governance.

In particular, middle management is a key position to help in the creation of an ethical culture. This may be developed through activities including talking frequently about the ethical values and ethical commitment of the organisation, and how the ethical values and commitments apply to the work of the specific group (Hanson, 2008). These ethical values are very important because they are instrumental factors in achieving high quality corporate governance. In fact, if middle and senior management have a primarily unethical culture, it is impossible for organisation to have the appropriate control environment or to practice high quality corporate governance.

When interpreting the results of this study, several limitations need to be considered. First, a limitation of this study relates to the small sample size. Since there were only 61 usable responses for this study, this may pose some constraints on the use of a structural equation model for this data analysis. However, the key indices for primary structural equation models, provided in the first paragraph of the Results of Hypotheses section, suggest the SEM for this study is a robust model. Also, the reported Hoelter critical $\mathrm{N}$ for the study's SEMs (i.e., primary SEM between 337 for .05 and 517 for .01; first alternative SEM between 246 for .05 and 425 for .01; second alternative SEM between 184 for .05 and 251 for .01 ) indicate that the posited models are correct and should be accepted for this sample size. ${ }^{15}$ Finally, the usual qualifications that are acknowledged for survey research are applicable to this study.

Future research may use the model developed in this study in a longitudinal study to investigate further the impact of the multidirectional iterative process assertions about the components of COSO's internal control framework and our findings of reciprocal associations (the cyclical nature of information communication with risk assessment and monitoring). For the control environment component, studies may undertake in-depth interviews of employees, which may provide a better understanding about how an ethical environment may help employees to share information and adhere more willingly to control policies. While the current findings relate to the Australian environment, future studies should be conducted in other countries. The need for such future studies is about the strengthening of the COSO framework because, according to Landsittel the COSO Chairman, the concept of effective controls and governance are relevant around the world (Tidrick, 2012). An extended scope of COSO's five components may be examined within the context of its application to small public corporations, or to small private

15 The $\mathrm{N}$ values are larger than the accepted critical $\mathrm{N}$ value of 200 argued by Hoelter (1983) and are considered adequate by Byrne (2001) and Arbuckle (2005). 
companies as suggested by Rittenberg (2006). The model developed in this study could be applied in such future research.

\section{References}

Agbejule, A., \& Jokipii, A. (2009). 'Strategy, control activities, monitoring and effectiveness'. $\begin{array}{llllll}\begin{array}{l}\text { Managerial Auditing Journal, } \\ \text { https://doi.org/10.1108/02686900910966503 }\end{array} & & & \text { Vol. 24, } & \text { pp. } & \end{array}$

Aikins, S. K. (2011). 'An examination of government monitorings role in improving financial performance', Public Finance and Management, Vol. 11, pp. 306-337.

Arbuckle, J. L. (2005). Amos ${ }^{\mathrm{TM}} 6.0$ User's Guide. United States of America: Amos Development Corporation.

Arena, M., \& Azzone, G. (2009). 'Identifying organizational drivers of monitoring effectiveness'. International Journal of Auditing, Vol. 13, pp. 43-60. https://doi.org/10.1111/j.10991123.2008.00392.x

Baines, A., \& Langfield-Smith, K. (2003). 'Antecedents to management accounting change: a structural approach', Accounting, Organizations and Society, Vol. 28, pp. 675-698. https://doi.org/10.1016/S0361-3682(02)00102-2

Banerjee, C., and Gupte A., 2015, Deloitte Global Trends in Corporate Governance, New Delhi: India

Brief, A. P., Dukerich, J. M., Brown P. R., \& Brett, J. F. (1996). 'What's wrong with the Treadway Commission report? Experimental analyses of the effects of personal values and codes of conduct on fraudulent financial reporting', Journal of Business Ethics, Vol. 15, pp. 183198. https://doi.org/10.1007/BF00705586

3yrne, B. M. (2001). Structural Equation Modeling with AMOS Basic Concepts, Applications, ad

Programming, Mahwah, N.J.: Lawrence Erlbaum Associates.

Callaghan, J. H. (2007). 'Assessing control environments using a balanced scorecard approach', The CPA Journal, March, pp. 58-63.

Zhtioui, T., \& Thiéry-Dubuisson, S. (2011). 'Hard and Soft controls: Mind the gap', International Journal Of Business, Vol 16, pp. 289-302.

Zohen, J., Krishnamoorthy, G., \& Wright, A. M. (2002). 'Corporate governance and the audit process', Contemporary Accounting Research, Winter, pp. 573-594. https://doi.org/10.1506/983M-EPXG-4YOR-J9YK

Zommittee of Sponsoring Organisations of the Treadway Commission, (2011). Internal Control Integrated Framework (Framework), December, [Electronic version] as viewed on www.ic.org, Novermber 2012.

Zommittee of Sponsoring Organisations of the Treadway Commission, (2004). 'Enterprise risk management - Integrated framework' [Electronic version], The Institute of Monitoringors.

Committee of Sponsoring Organisations of the Treadway Commission, (1992). 'Internal control Integrated framework, [Electronic version], The Institute of Monitoringors.

IPA Australia (2003). Small Business Survey Program: Financial Management, Insolvency and 
Rae, Sands \& Subramaniam | Associations Among five Components COSO as an Underpinning of Corporate Governance

Fraud. Melbourne: CPA Australia.

D'Aquila, J., \& Bean, D. F. (2003). 'Does a Tone at the Top that fosters ethical decisions impact financial reporting decisions: An experimental analysis', International Business \& Economics Research Journal, Vol 2, pp. 41-53.

Dai, L. (2011). 'Research on enterprise risk control information system: The case of CIC', Conference: Artificial Intelligence, Management Science and Electronic Commerce (AIMEC). http://ieeexplore.ieee.org/xpls/abs_all.jsp?arnumber=6010527

Dechow, P., \& Skinner, D. (2000). 'Earnings management: Reconciling the views of accounting academics, practitioners, and regulators', Accounting Horizons, pp. 235-250. https://doi.org/10.2308/acch.2000.14.2.235

Downs, C.W. (1988). Communication Audits. Glenview, Illinois: Scott, Foresman and Company.

Du Plessis, JJ, Hargovan, A. Bagaric, M \& Harris, J., (2015), Principles of contemporary corporate governance, 3rd edn, Cambridge University Press, Port Melbourne, Victoria

Fatemi, A., \& Glaum, M. (2000). 'Risk management practices of German firms', Managerial Finance, Vol. 26, pp. 1-17. https://doi.org/10.1108/03074350010766549

Ford, R. (2006). 'Organizational learning, change and power: toward a practice-theory framework', The Learning Organization, Vol. 13, pp. 495-524. https://doi.org/10.1108/09696470610680008

Goodwin-Stewart, J., \& Kent, P. (2006). 'The use of monitoring by Australian companies', Managerial Auditing Journal, Vol 21, pp. 81-101. https://doi.org/10.1108/02686900610634775

Hanson, K.,(2008) Ethics and the Middle Manager: Creating "Tone in The Middle", https://www.scu.edu/ethics/focus-areas/business-ethics/resources/ethics-and-the-middlemanagertone-in-the-middle/ (viewed 25 November 2016)

Healy, P. M., \& Palepu, K. G. (2003). ‘The Fall of Enron', The Journal of Economic Perspectives. Vol. 17, pp. 3-26. https://doi.org/10.1257/089533003765888403

Hoelter, J. W. (1983). 'The Analysis of Covariance Structures: Goodness-of-Fit Indices', Sociological Methods \& Research, February, Vol. 11, pp. 325-344.

Hu, L-T., \& Bentler, P.M. (1999). 'Cutoff criteria for fit indexes in covariance structure analysis: Conventional criteria versus new alternatives'. Structural Equation Modeling: A Multidisciplinary Journal, Vol. 6, pp. 1-55. https://doi.org/10.1080/10705519909540118

Hunt, S. D., Wood, V. R., \& Chonko, L. B. (1989). 'Corporate ethical values and organizational commitment in marketing', Journal of Marketing, Vol. 53, pp. 79-91. https://doi.org/10.2307/1251344

Hutt, M. D., Stafford, E. R., Walker, B. A., \& Reingen, P. H. (2000). 'Case Study: Defining the Social Network of a Strategic Alliance', Sloan Management Review; Winter, Vol 41, pp. 51-62.

[moniana, J O., Costa, V. M., Luiza, M. A., Alberto, H. P., and Alves, P. P. (2011) "Causality and multidimensionality of internal controls: impact on organizations", Corporate Ownership \& Control, Volume 8, Issue 2, Winter, pp. 502-515. 
Johnstone, K., Li, C., \& Rupley, K. H. (2011). 'Changes in corporate governance associated with the revelation of internal control material weaknesses and their subsequent remediation', Contemporary Accounting Research, Vol. 28, pp. 331-383. https://doi.org/10.1111/j.1911$\underline{3846.2010 .01037 . x}$

Iokipii, A. (2010). 'Determinants and consequences of internal control in firms: A contingency theory based analysis', Journal of Management and Governance, Vol. 14, pp. 115-144. https://doi.org/10.1007/s10997-009-9085-x

Kalbers, L. P. (2009). 'Fraudulent financial reporting, corporate governance and ethics: 19872007', Review of Accounting \& Finance, Vol. 8, pp. 187-209. https://doi.org/10.1108/14757700910959510

Kayes, D. C., Stirling, D., \& Nielsen, T. M. (2007). 'Building Organizational Integrity', Business Horizons, Vol. 50, pp. 61-70. https://doi.org/10.1016/j.bushor.2006.06.001

Kinney, W. R. (2003). Auditing risk assessment and risk management processes, The Institute Of Monitoringors Research Foundation, Altamonte Springs, Florida.

Kline, R. B. (1998). Principles and practice of structural equation modeling, New York: The Guilford Press.

Krishnan, G. V. (2003). 'Audit quality and the pricing of discretionary accruals', Auditing, Vol. 22, pp. 109-127. https://doi.org/10.2308/aud.2003.22.1.109

Lindow, P.E., \& Race, J. D. (2002)., 'Beyond traditional audit techniques'. Journal of Accountancy, Vol. 194, pp. 28-34.

Mandaci, P., E.; Kahyaoglu, S. B,, (2012), 'The role of internal auditing and corporate governance in enterprise risk management: empirical evidence on nonfinancial firms listed in Istanbul stock exchange', World of Accounting Science, Vol. 14 Issue 1, p 43-66.

Michelman J. E., \& Waldrup, B. E. (2008). 'Improving internal control over financial reporting: COSO's guidance not just for public companies anymore', The CPA Journal, pp. 30-34.

Moeller, R. (2007). 'COSO Enterprise Risk Management: Understanding the new integrated ERM framework', New Jersey, USA, Wiley.

Morrison, M., \& Terziovski, M. (2001). 'Quality management practices and the link to potential learning outcomes within the Australian retail sector', The Learning Organization, Vol. 8, pp. 176-186.

Nunnally, J. (1978). Psychometric theory. $2^{\text {nd }}$ Ed. New York: McGraw-Hill cited in Govindarajan, V. 1988. A contingency approach to strategy implementation at the business unit level: integrating administrative mechanisms with strategy. Academy of Management Journal, Vol. 31, pp. 828-853.

Nunnally, J.C., \& Bernstein, I. H. (1994). Psychometric Theory. $3^{\text {rd }}$ Ed. New York; Sydney: McGraw-Hill.

J’Reilly C. A. III., \& Roberts, K. H. (1976). 'Relationships among components of credibility and communication behavior in work units', Journal of Applied Psychology, Vol. 1, pp. 99-102. https://doi.org/10.1037/0021-9010.61.1.99

Rae, K. N., Subramaniam, N., \& Sands, J. S. (2008)., 'Risk Management and Ethical Environment: 
Rae, Sands \& Subramaniam | Associations Among five Components COSO as an Underpinning of Corporate Governance

Effects on Monitoring and Accounting Control Procedures'. Journal of Applied Management Accounting Research Vol. 6, pp. 11-30.

Ratnatunga, J., \& Alam, M. (2011). 'Strategic governance and management accounting: Evidence from a case study', Abacus, Vol. 47, pp. 343-382. https://doi.org/10.1111/j.1467$\underline{6281.2011 .00344 . x}$

Rittenberg, L. E. (2006). 'Internal control: no small matter', The Monitoringor, October, Vol. 63, pp. 47-51.

Schumaker, R.E., \& Lomax, R. G. (1996). A beginner's guide to structural equation modeling. NJ: Lawrence Erlbaum associates. https://doi.org/10.1080/10705519609540025

Simmons, M. R. (1997a)., 'COSO based auditing', The Monitoringor, December, Vol. 54, No. 6, pp. 68-73.

Simmons, M. R. (1997b). 'The standards and the framework', The Monitoringor, April, Vol. 54, pp. 50-55.

Simmons, M. R. (2008). 'Monitoring Objectives: A Comparison of the Standards with the Integrated Framework for Internal Control', http://www.facilitatedcontrols.com/internalauditing/spiacoso.shtml [accessed 10 November, 2008]

Stringer, C., \& Carey, P. (2002). 'Internal Control Re-design: An Exploratory Study of Australian Organisations', Accounting, Accountability and Performance, Vol. 8, pp. 61-86.

Tabachnick, B. G., \& Fidell, L. S. (2001), Using Multivariate Statistics, $4^{\text {th }}$ edition, Boston: Allyn and Bacon.

Ticehurst, G.W., \& Downs, C. W. (1998). 'Professional communication in Asia/Pacific organisations: A comparative study', 1998 NIC Symposium on Intercultural Communication, Goteborg, Sweden.

Tidrick D. E., (2012) 'Improving Governance and Internal Control - An Interview with COSO Chairman David L. Landsittel', The CPA Journal, October, pp. 6-11.

Van Peursem, K. (2004)., 'Monitoringor's role and authority: New Zealand evidence', Managerial Auditing Journal, Vol. 19, pp. 378-387. https://doi.org/10.1108/02686900410524382

Verschoor, C. C., \& Farrell, T. (1996). 'Questions directors should ask before outsourcing the monitoring function', Directors Monthly, December, pp. 5-7.

Viator, R. E. (2001). 'The association of formal and informal public accounting mentoring with role stress and related job outcomes', Accounting, Organizations and Society, Vol. 26, pp. 73-93. https://doi.org/10.1016/S0361-3682(00)00002-7

Vîlsănoiu, D., \& Şerban, M. (2010). 'Changing methodologies in financial audit and their impact on information systems audit', Informatica Economică, Vol. 14, pp. 57-65.

Weaver, G. R., Trevino, LK, \& Cochran, P.L. (1999b). 'Integrated and decoupled corporate social performance: Management commitments, external pressures, and corporate ethics practices', Academy of Management, October 1, 42:5, pp. 539-552.

Weaver, G. R., Trevino, LK, \& Cochran, P.L. (1999a). 'Corporate ethics programs as control systems: Influences of executive commitment and environmental factors', Academy of 
Management, February 1, 42:1, pp. 41-57.

Weaver, G. R., Trevino, LK, \& Cochran, P.L. (1999b). 'Integrated and decoupled corporate social performance: Management commitments, external pressures, and corporate ethics practices', Academy of Management, October 1, 42:5, pp. 539-552.

Young, P. C. (2004). 'Ethics and risk management: Building a framework', Risk Management: An International Journal Vol. 6, pp. 23-34.

Zablow, R. J. (2006). 'Creating and sustaining an ethical workplace', Risk Management, Vol. 53, pp. 26-30. 